\title{
PROGRAMAS DE ACELERAÇÃO DE STARTUPS NO BRASIL: CARACTERÍSTICAS CENTRAIS E QUESTÕES ABERTAS
}

Stéfany Dayana de Sá Rocha (stefany-dayana@ hotmail.com) - Universidade Federal de Minas Gerais

Raoni Barros Bagno (rbagno@ dep.ufmg.br) - Universidade Federal de Minas Gerais

\section{RESUMO}

Atualmente o Brasil possui um número considerável de programas de aceleração de startups distribuídos em seu território. Contudo, são escassos os estudos e pesquisas acadêmicas sobre o assunto. $O$ presente trabalho identifica as principais características que definem e qualificam os programas de aceleração de startups no país através de consultas às bibliografias clássicas e editais elou informações públicas sobre tais programas. Foram analisados 49 programas no país e suas principais características e parâmetros foram agrupados em nove categorias: (i) geral e status; (ii) foco de atuação; (iii) governança; (iv) internacionalização; (v) etapas; (vi) atividades; (vii) natureza processo seletivo; (viii) investimento e remuneração; e (ix) finalização do programa. Após uma revisão descritiva dos programas, é realizada uma discussão dos perfis, características e parâmetros qualificadores dos programas de aceleração de startups no Brasil. Por meio de uma reflexão sobre as características convergentes e divergentes entre os programas analisados, o texto oferece uma análise das iniciativas no país e levanta novas questões a serem consideradas por gestores no projeto $e$ condução de programas de aceleração de startups e aprofundadas por novos esforços de pesquisa.

Esta publicação contou com o apoio financeiro da Fundação de Amparo à Pesquisa do Estado de Minas Gerais (FAPEMIG).

Palavras-chave: Programas de aceleração de Startups; Startup; Empreendedorismo de Base Tecnológica; Inovação.

Área: Inovação e a gestão do desenvolvimento de produtos e serviços em empresas no Brasil

\section{INTRODUÇÃO}

O fenômeno conhecido como aceleração de startups é relativamente novo no mundo (PAUWELS, 2014). A primeira iniciativa de um programa de aceleração remete ao surgimento da aceleradora Y Combinator, em 2005, nos Estados Unidos da América (EUA) (MILLER; BOUND, 2011; COHEN, HOCHBERG, 2014; DEMPWOLF et al., 2014). A partir daí, esforços semelhantes se espalharam pelo mundo e chegou ao Brasil entre os anos de 2010 e 2011 (AGUILHAR, 2014; SALIDO et al., 2013). Em 2012 foi lançado no país o Programa Nacional de Aceleração, o Start-Up Brasil, uma iniciativa do Ministério da Ciência, Tecnologia e Inovação (MCTI), com o objetivo de perdurar até o ano de 2020. O programa em um primeiro momento, se destinou às empresas de software e serviços (CNI, 2016) e estimulou o desenvolvimento de outros programas de aceleração de startups em todo o país, no entanto, o mesmo foi suspenso no ano de 2014.

Apesar do crescente interesse no modelo de aceleração pelas comunidades de investimento, educação empresarial e políticas públicas, houve poucas tentativas de análise do fenômeno (MILLER; BOUND, 2011; TASIC et al., 2015; SMITH; HANNIGAN, 2015). Também são escassas as evidências sobre o papel e a eficácia dos programas de aceleração de startups, mesmo com o aumento significativo de aceleradoras e autoridades locais que adotaram o 
modelo de acelerador (FEHDER; HOCHBERG, 2014). Por isso, o fenômeno conhecido como aceleração de startups representa um campo ainda pouco explorado e, consequentemente, não completamente compreendido (ROMAN, 2017).

No entanto, estudos recentes no país têm abordado temas como ecossistema de inovação, startups e aceleradoras. Uma pesquisa realizada por Faria et. al. (2017) construiu um diagnóstico do ecossistema inovador em Minas Gerais considerando empresas, incubadoras e parques tecnológicos. Ainda nesse sentido, uma pesquisa realizada por Abreu e Campos (2016) analisou o papel das aceleradoras de startups no país. Diferentemente de esforços de pesquisa anteriores, este trabalho foca nos programas de aceleração, e busca resposta à seguinte questão de pesquisa: quais são as principais características dos programas de aceleração de startups no Brasil? Deste modo, o presente estudo busca uma análise ampla dos perfis, características e parâmetros qualificadores dos programas de aceleração de startups no Brasil através da análise de dados secundários possibilitando a identificação dos principais critérios e/ou propriedades, denominados de parâmetros neste trabalho, que: (i) geram semelhanças e/ou diferenciações nos programas de aceleração de startup no país; e (ii) definem e/ou qualificam um programa de aceleração de startup brasileiro. A partir destes parâmetros pretende-se analisar e comparar os programas de aceleração de startups identificados no país.

\section{EMPREENDEDORISMO INOVADOR}

O termo "empreendedorismo inovador" corresponde ao trabalho conjunto ou associação do empreendedorismo com a inovação (MARTINS, 2013; SARKAR, 2008). Segundo Leite (2008), a figura do empreendedor inovador tomou relevância a partir da década de 1970 e para Dolabela (1999), o empreendedor inovador é o responsável pelo desenvolvimento de inovações no âmbito dos negócios. Dentre as diferentes tipologias de empreendedor, o inovador é aquele que corresponde ao stricto sensu e que se arrisca na aplicação de inovações em uma busca sistemática de oportunidades (AVENI, 2014).

Neste contexto, surge também o fenômeno das startups que estão diretamente relacionadas ao empreendimento inovador (OLIVEIRA, 2014) e possibilitam a geração de novas tecnologias (THIEL; MASTERS, 2014). Além disso, os empreendedores que criam startups, geralmente, são inovadores em diversas dimensões (DUARTE et. al., 2015). Ainda para Duarte et al. (2015) a inovação em startups é um dos mais complexos temas presentes na literatura, sendo que frequentemente está relacionado a inovações radicais e seus empreendedores podem ser considerados inovadores seriais em múltiplas dimensões, ou seja, não restritos apenas à produtos.

\subsection{Startups}

Dentre as definições de startup que mais se difundiram tanto no meio acadêmico quanto profissional, é possível destacar: (i) "uma instituição humana projetada para criar novos produtos e serviços sob condições de extrema incerteza" (RIES, 2011); (ii) "uma organização temporária em busca de um modelo de negócios escalável, repetível e lucrativo" (BLANK e DORF, 2012). Para Andrade (2012) as startups são caracterizadas pelo potencial de crescimento, criação de conhecimento e riquezas, orientação pela tecnologia e inovação, sendo um tipo específico de empresa iniciante. Ainda segundo ele, as startups mesclam criatividade, pesquisa, inovação e incertezas.

De acordo com a Startup Commons (2016) são três os estágios de desenvolvimento de uma startup: (i) formação: estágio que antecede o desenvolvimento do negócio; (ii) validação: 
estágio de desenvolvimento inicial do negócio, de criação do Minimum Viable Product (MVP) e de validação da ideia como um todo, também momento da busca por mercados; e (iii) crescimento: quando a startup se estabelece e ganha espaço ao mercado (Quadro 1).

Quadro 1. Estágios de desenvolvimento de uma startup.

\begin{tabular}{|c|c|c|}
\hline Estágio & Etapas & Descrição \\
\hline \multirow[b]{2}{*}{ Formação } & Ideação & Criação da solução, caracterizada por uma pequena equipe e pouca estrutura de negócio. \\
\hline & Concepção & $\begin{array}{l}\text { O modelo de negócio é estruturado, a missão/visão da empresa é definida, a estratégia inicial e } \\
\text { os prazos iniciais são definidos e, neste momento, membros adicionais podem entrar no } \\
\text { empreendimento. }\end{array}$ \\
\hline \multirow[t]{2}{*}{ Validação } & Comprometimento & $\begin{array}{l}\text { A visão é replicada para todo o time juntamente com os valores e as atitudes, a primeira versão } \\
\text { do produto ou serviço é elaborada e testada, investimentos em dinheiro são feitos na startup } \\
\text { (geralmente, por parte dos membros fundadores) para alavancar o seu crescimento, e a aceitação } \\
\text { no mercado é feita. }\end{array}$ \\
\hline & Validação & As premissas são testadas e validadas e, geralmente, surgem os primeiros sinais de crescimento. \\
\hline \multirow[b]{2}{*}{ Crescimento } & Escalar o negócio & $\begin{array}{l}\text { Foco na captação de consumidores. São realizadas contratações, melhorias no proces so e na } \\
\text { qualidade do produto e/ou serviço. }\end{array}$ \\
\hline & Consolidação & $\begin{array}{l}\text { O crescimento já foi atingido e pessoas e investidores se sentem atraídos pelo negócio } \\
\text { desenvolvido, investidores de capital sementes começam a sair da empresa e retirar seus lucros, } \\
\text { e a empresa começa a funcionar sozinha. }\end{array}$ \\
\hline
\end{tabular}

Fonte: Elaborado pelos autores.

Para Ries (2011) e Turion (2012) a maioria das startups não são exitosas e o sucesso de uma startup pode ser alcançado ao se seguir um processo correto, que pode ser aprendido pelos empreendedores. Para Dee et al. (2015) as startups enfrentam uma série de desafios e oportunidades únicos e requerem ajuda de uma variedade de iniciativas e/ou programas de apoio. Arruda et al. (2013) afirmam que o local de alojamento de uma startup é capaz de definir as suas chances de êxito e instituições como parques tecnológicos, incubadoras e aceleradoras são fundamentais para um ecossistema empreendedor, por serem capazes de diminuir as chances de descontinuidade de uma startup.

\section{PROGRAMAS DE ACELERAÇÃO DE STARTUPS}

Para Cohen e Hochberg (2014), ainda não se tem um consenso na literatura quanto à definição de programas de aceleração de startups e a heterogeneidade entre os programas atuais de aceleradores obscurece ainda mais a pesquisa nesta área. Por isso, neste trabalho adotaremos o seguinte conceito para os programas de aceleração de startups: são programas de duração limitada que assistem as startups no processo de implantação de empreendimento, oferecendo oportunidades de networking com empresários bem sucedidos, capitalistas de risco, investidores anjo, entre outros (COHEN, 2013; HOFFMAN; RADOJEVICH-KELLEY, 2012).

Os programas de aceleração de startups são caracterizados por proporcionar aporte de capital, oferecer mentorias, parcerias, local para estadia e trabalho, entre outros (PERIN, 2015; COHEN, 2013; DEE et al., 2015; CLARYSSE et al., 2015; HOFFMAN; RADOJEVICHKELLEY, 2012). Tais programas representam assim, um modelo relativamente novo de assistência aos empreendedores que combina muitos recursos que no passado eram normalmente fornecidos separadamente (COHEN; HOCHBERG, 2014). Há, normalmente, variações entre os programas, mas todos eles compreendem cinco características principais: (i) Um processo de candidatura aberto a todos, mas altamente competitivo; (ii) Provisão de investimento pré-semente, geralmente em troca de capital próprio; (iii) Foco em equipes pequenas em detrimento de fundadores individuais; (iv) Apoio limitado ao tempo que inclui eventos programados e mentorias; e (v) Grupo ou "classes" de startups em vez de empresas individuais (MILLER, BOUND, 2011). 


\section{METODOLOGIA}

A pesquisa consistiu em três fases principais: (i) Revisão bibliográfica; (ii) levantamento dos dados secundários do maior número possível de programas de aceleração no país; e (iii) análise dos dados coletados (Figura 1).

Figura 1 - Fases do desenvolvimento da pesquisa.

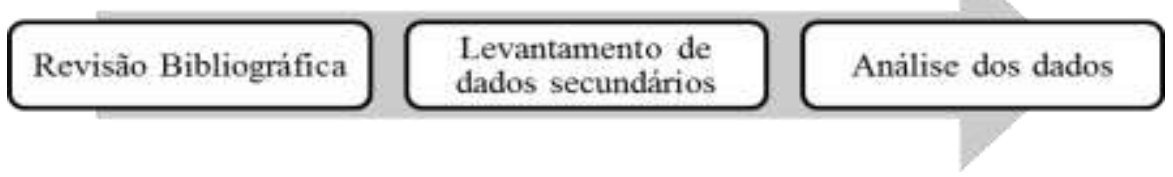

Fonte: Elaborado pelos autores.

A princípio foram elencados parâmetros a partir da revisão da literatura e a cada programa de aceleração encontrado no país era possível analisar, adicionar ou retirar um parâmetro e/ou característica elencado anteriormente. Por fim, notou-se que havia se identificado as principais características dos programas de aceleração no país, pois a inclusão de novos programas no estudo não mais possibilitava o acréscimo de novos parâmetros. Ao todo foram 49 programas de aceleração de startups no país identificados na pesquisa. Finalizadas então a identificação de tais informações, e com o intuito de facilitar a análise, tais parâmetros foram classificados de acordo com as semelhanças de assuntos e temas totalizando 9 categorias: (i) geral e status; (ii) foco de atuação; (iii) governança; (iv) internacionalização; (v) duração e fases; (vi) atividades; (vii) natureza processo seletivo; (viii) Investimento e remuneração; e (ix) finalização do programa.

Para o levantamento de dados secundários de programas de aceleração de startups no país foram utilizados palavras e termos como "programa de aceleração de startups" e "programa de apoio às startups" em sites de busca aberta como o Google. O objetivo era a identificação de programas que possuíam editais e/ou chamadas públicas com informações suficientes para agregar ao acervo, ou seja, que possuíam informações referentes a pelo menos metade dos parâmetros já identificados e/ou sugeriam a consideração de novos parâmetros. As principais fontes de informações sobre estes programas foram editais e/ou sites oficiais, no entanto, algumas informações adicionais foram pesquisadas em sites de notícia, blogs, entre outros. Além disso, algumas informações foram obtidas ou validadas através do contato direto via redes sociais, e-mail e telefone.

\section{ANÁLISES E RESULTADOS}

Foram identificados 49 programas de aceleração com edições entre 2015 e primeiro semestre de 2017, dentre eles, 5 possuíam atuação em mais de uma cidade. Encontraram-se programas em atuação em todas as regiões do país: norte (5), nordeste (3), centro-oeste (4), sudeste (38) e sul (11). A listagem dos parâmetros e categorias encontra-se no Quadro 2.

\section{Foco de atuação dos programas de aceleração de startups}

Os programas identificados na pesquisa foram classificados de acordo com o estágio de maturidade da startup conforme tipologia proposta pela Startup Commons (2016). Alguns programas se mostraram com uma clara delimitação com relação ao estágio da startup que pretendiam trabalhar, outros já mesclavam duas ou até mesmo as três fases. Na Figura 2 é possível observar que o número de programas que especificaram de alguma forma a intenção de atuação em determinado setor (saúde, TI, energia, outros) supera o número de programas que não possuem restrição de setor ou que não deixaram claro ou não informaram (NI) sobre esta intenção. 
Quadro 2 - Listagem dos parâmetros

\begin{tabular}{|c|c|}
\hline Agrupamento & Parâmetro \\
\hline \multirow{3}{*}{ Geral e Status } & Localizacão no Brasil \\
\hline & Status do programa (em abril/2017) \\
\hline & Ano de selecão do edital/chamada pública analisado \\
\hline \multirow{3}{*}{ Foco de Atuação } & Estágio da startup acelerada \\
\hline & Tipo de negóciol tecnologia \\
\hline & Setor foco de atuaç̃o \\
\hline \multirow{3}{*}{ Governança } & Tipo da instituicão(ões) responsável(is) pelo programa \\
\hline & Parceiros oficiais do programa \\
\hline & Aceleradora oficialmente vinculada ao programa? \\
\hline \multirow{2}{*}{ Internacionalização } & Foco na possibilidade de internacionalizaç̃o \\
\hline & Restricão quanto à inscricão de candidatos estrangeiros \\
\hline \multirow{5}{*}{$\begin{array}{c}\text { Duração e Fases do } \\
\text { Programa }\end{array}$} & Duraç̃o aproximada do programa \\
\hline & Número de fases/ etapas principais do programa \\
\hline & Descricão das fases/etapas dos programas \\
\hline & Possui fases/etapas eliminatórias \\
\hline & Possui demo dav? Termina em demo dav? \\
\hline \multirow{4}{*}{ Atividades } & Tipo de apoio \\
\hline & Estrutura fisica para apoio \\
\hline & Principais conexões/ rede \\
\hline & Principais atividades/iniciativas do programa \\
\hline \multirow{3}{*}{$\begin{array}{c}\text { Natureza Processo } \\
\text { Seletivo }\end{array}$} & Tipo de convocacão para inscricões \\
\hline & Pessoas por projetol startup \\
\hline & Critérios de selecão \\
\hline \multirow{3}{*}{$\begin{array}{l}\text { Investimento e } \\
\text { Remuneração }\end{array}$} & Opcões de investimento financeiro (aproximado) \\
\hline & Participacão acionária na startup participante do programa \\
\hline & Contrapartida financeira da startup \\
\hline \multirow[t]{2}{*}{ Graduação } & $\begin{array}{l}\text { Startup }(\mathrm{s}) \text { vencedora }(\mathrm{s}) \\
\text { Possui premiacĩ para startup (s) oraduadas eloll vencedoras }\end{array}$ \\
\hline & Possui premiacaio para startup (s) graduadas e/ou vencedoras \\
\hline
\end{tabular}

Fonte: Elaborado pelos autores.

Já com relação ao negócio das startups, foi possível identificar que grande parte dos programas eram generalistas ou não especificaram os tipos de tecnologias aceitas para participação no programa. Já com relação aos programas que possuem foco, se destacam: (i) tecnologia digital: diz respeito à tecnologia da informação (TI) e aos projetos com foco em software como, por exemplo, games, software em geral, entre outros; (ii) hardware: pode ser definido como equipamento mecânico necessário para realização de uma determinada atividade; (iii) hard science: projetos científicos que podem ser baseados na física, química, bioquímica, entre outros.

Figura 2 - Foco de atuação em setor segundo os programas analisados

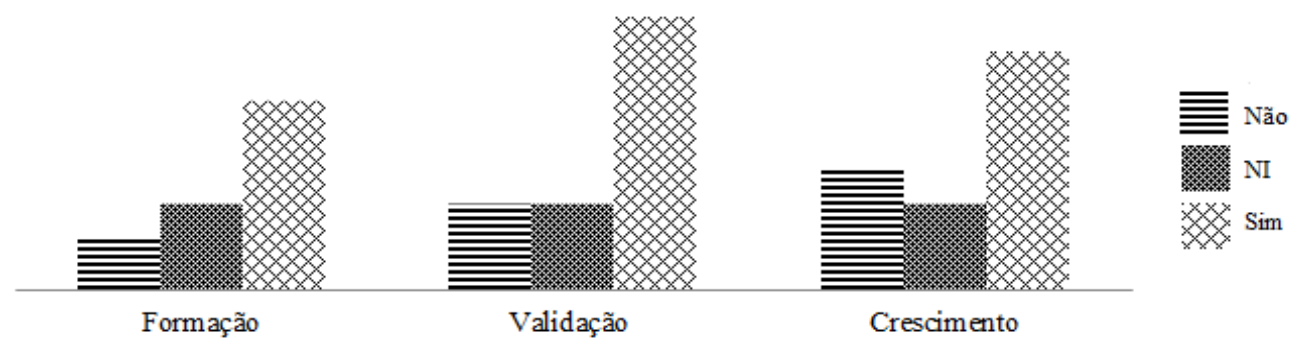

Fonte: Elaborado pelos autores.

\section{Governança dos programas de aceleração de startups}

Foram identificados os seguintes agentes que atuam como governantes e/ou parceiros em programas de aceleração de startups: empresas, incubadoras, associações de empresas privadas, governo, universidade, aceleradora e parque tecnológico. Na Figura 3 é possível observar que as aceleradoras são as principais atuantes como gestores principais nos programas estudados e dentre os 49 programas analisados, pelo menos 32 contemplavam a atuação oficial de uma aceleradora de startups. 
Figura 3 - Governança dos programas pesquisados

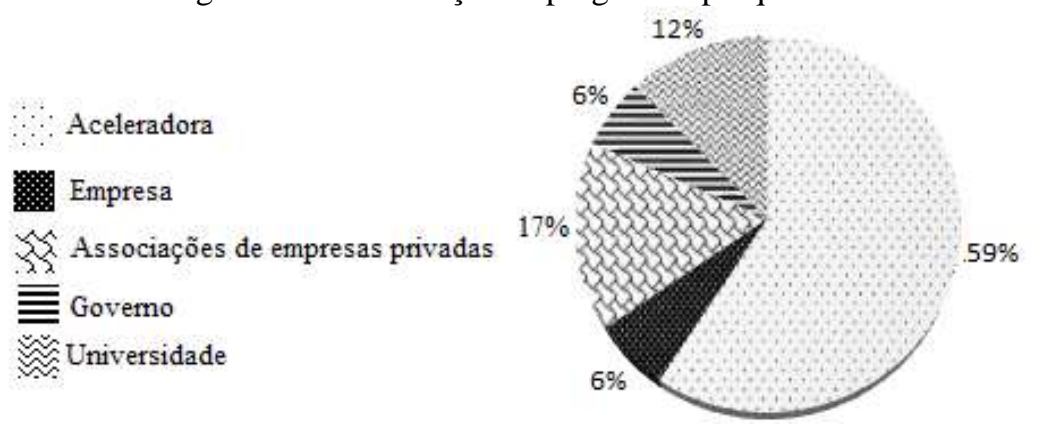

Fonte: Elaborado pelos autores.

\section{Internacionalização}

Em apenas um programa foi observado restrição quanto a inscrição de candidatos estrangeiros ao se exigir a presença de no mínimo um cidadão brasileiro na equipe. Para tal conclusão, foi interpretado que os programas que não abordavam o assunto em seus principais meios de divulgação não possuíam o interesse na restrição. Além disso, pelo menos $34 \%$ dos programas evidenciaram parcerias no exterior para possíveis atuações juntamente com as startups participantes e/ou demonstraram o interesse explícito na atuação além das fronteiras nacionais. No entanto, o fato de um programa não ter sido considerado com foco na internacionalização, não significa que esta não possa ocorrer em alguns casos.

\section{Duração e Fases dos programas de aceleração de startups}

Apesar da existência de programas de longa duração (até 18 meses) no universo pesquisado, cerca de $70 \%$ dos programas apresentam duração de até 6 meses. Ao todo, foram 23 programas que divulgaram suas etapas e, dentre eles, foi identificado um programa com 4 fases, no entanto, geralmente os mesmos possuem de 2 a 3 etapas. Tais fases dizem respeito a um período pré-determinado em que são destinadas atividades e iniciativas para se lograr determinado objetivo e podem ou não coincidir com as fases de desenvolvimento de startups proposta pela Startup Commons (2016). Além disso, pelo menos 26 dos 49 programas possuem demo day, ou dia de demonstração, que consiste na presentação das empresas que passaram pela aceleração a investidores (RODRIGUEZ, 2015; COHEN, 2013). Dentre estes, 15 finalizam o programa com o evento. Além disso, foi identicado que pelo menos 6 programas adotavam o sistema de fases eliminatórias.

\section{Principais atividades e iniciativas dos programas de aceleração de startups}

Dentre os programas analisados, pelo menos, 18\% são parcialmente ou totalmente online, $76 \%$ possuem escritório compartilhado ou espaço de coworking e $12 \%$ disponibilizam acesso a laboratórios para execução de pesquisas. Foi possível também identificar: (i) principais conexões e redes: mentores, investidores, outras startups, especialistas, consultores e empreendedores e/ou executivos; (ii) principais atividades e iniciativas dos programas: treinamentos, aulas e/ou cursos; workshops; encontros e/ou reuniões; acesso a network; palestras; auxílio jurídico, contábil e/ou fiscal; e consultoria em marketing e/ou assessoria de imprensa.

\section{Investimento e Remuneração}

Dentre os programas analisados e que adotam o modelo de participação acionária nas startups foi observada uma prática de equity entre $5 \%$ a $15 \%$. Além disso, foram identificados, ao 
todo, 21 programas que fazem aporte financeiro nas startups. Cerca de $67 \%$ destes correspondem à investimento entre $\mathrm{R} \$ 50$ mil e $\mathrm{R} \$ 200$ mil.

\section{Finalização do Programa de Aceleração de Startups}

Alguns programas possuem premiação para as startups vencedoras e/ou graduadas no programa. Na Tabela 1 é possível visualizar as principais premiações identificadas em 11 programas de aceleração.

Tabela 1- Premiação startups graduadas ou vencedoras

\begin{tabular}{lr}
\hline Premiacão & $\mathbf{N}^{\mathbf{0}}$ de programas \\
\hline Período de aceleração e/ou acesso à outros programas de aceleração & 7 \\
Investimento & 2 \\
Investimento e acompanhamento & 1 \\
Não especificado & 1 \\
\hline
\end{tabular}

Fonte: Elaborado pelos autores.

\section{Processo de Seleção de Startups}

Dentre os programas analisados, 31 apresentavam o número de vagas para startups no respectivo programa. Dentre eles, aproximadamente $65 \%$ buscava a seleção de até 15 startups para a participação no programa de aceleração, $26 \%$ entre 16 a 40 startups e apenas 3 programas, representando um universo de $9,7 \%$ objetivavam uma captura em alta escala com 100 ou mais startups. A maior parte dos progrmas eram direcionados para equipes em detrimento de inscrições individuais. Já os principais critérios de seleção das startups podem ser observados na Figura 4 que evidencia o destaque para o seguintes critérios: (i) perfil da equipe: aspectos ligados aos integrantes da equipe como perfil empreendedor, experiência, entre outros; (ii) mercado: diz respeito às características do mercado no qual a startup pretende atuar como tamanho, perfil, etc.; e (iii) Grau de inovação: relaciona-se ao grau de novidade da tecnologia proposta.

Figura 4 - Principais critérios de seleção de startups identificados nos programas analisados

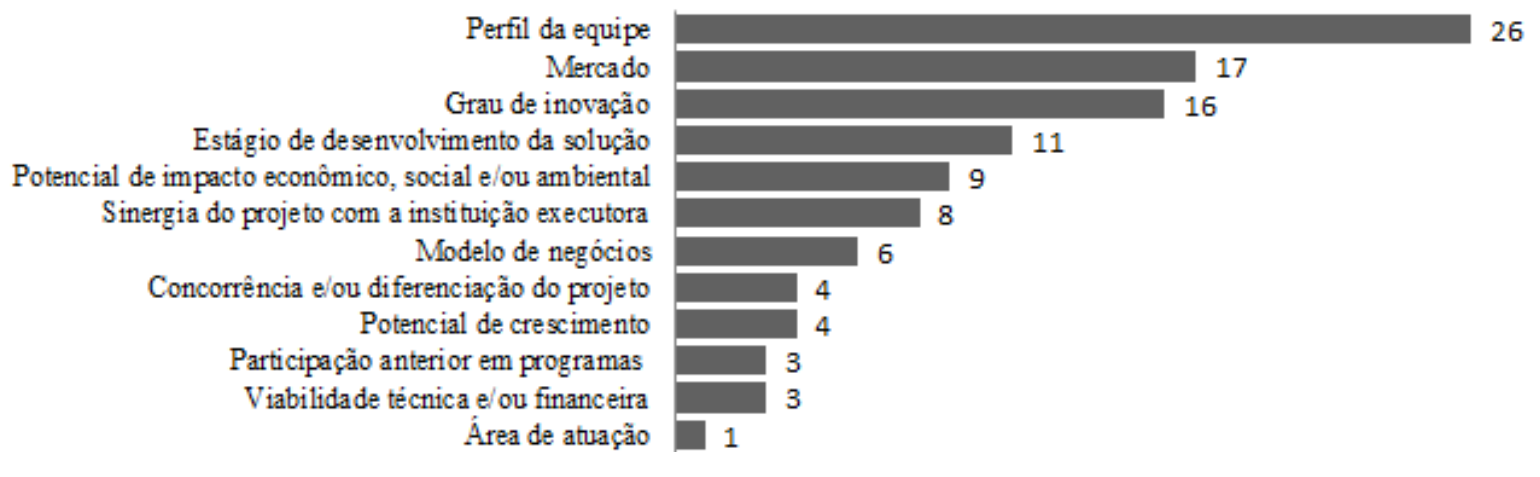

Fonte: Elaborado pelos autores.

\subsection{Considerações Gerais}

O levantamento de dados possibilitou a identificação do perfil dos programas brasileiros, mas também evidenciou questões que ainda não foram respondidas pela literatura sobre o assunto. Além disso, foi possível observar que, em geral, os programas de aceleração de startups no Brasil tencionam o fomento de startups a partir de: (i) processo de seleção; (ii) etapas previamente determinadas na execução do programa; e (iii) apoio de uma rede, tanto interna quanto externa, de mentores, especialistas, entre outros (Figura 5).

Além disso, os programas de aceleração de startups podem ou não possuir: (i) foco em um setor específico de atuação; (ii) foco em determinado tipo de negócios; (ii) etapas 
eliminatórias; (iii) etapas e/ou atividades remotas ou online. Também foram identificados programas com: (i) processo contínuo de seleção ou editais e chamadas públicas; (ii) possibilidade de inscrição por indivíduos ou equipes; (iii) exigência de CNPJ para inscrição; (iv) exigência de contrapartida financeira da startup participante; e (v) premiação para as startups que finalizam o programa de aceleração. No entanto, pouco se sabe sobre as principais diferenças, similaridades, vantagens e desvantagens entre tais modelos.

Figura 5 - Esquema geral de um programa de aceleração de startups

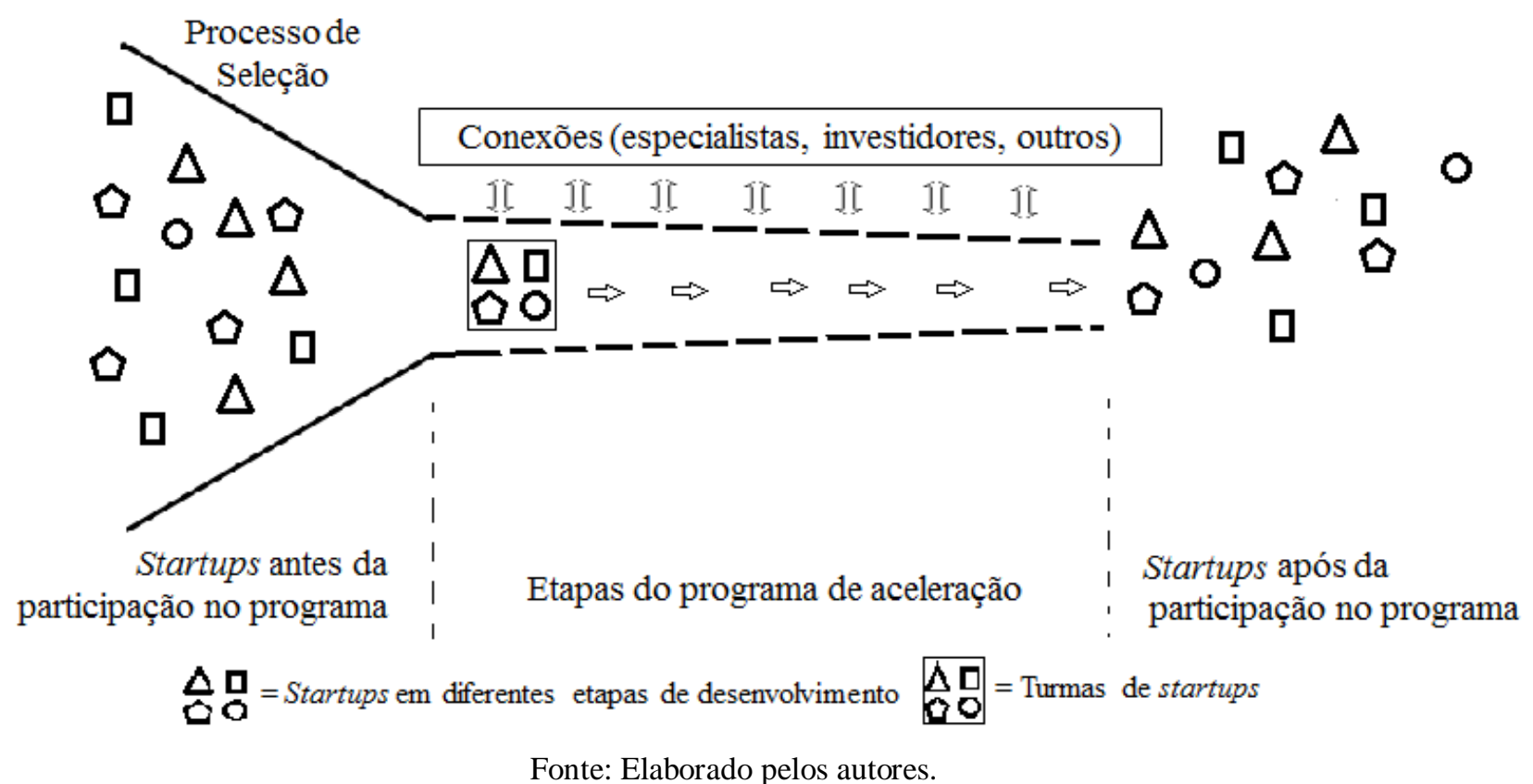

Observa-se também uma concentração dos programas de aceleração de startups na região sudeste do país. Além disso, grande parte dos programas de aceleração parece ter um viés voltado para negócios baseados em software, mesmo que isso não seja uma opção explícita do programa. Sabe-se, contudo, que muitas startups não se enquadram nesse perfil. Alguns programas de aceleração de startups em seu processo seletivo pontuam positivamente startups que já tenham participado de outros programas de aceleração. No entanto, não está claro ainda em quais aspectos essa prática pode ser considerada positiva ou negativa.

\section{CONCLUSÕES}

A partir da revisão bibliográfica e das informações coletadas através de dados secundários sobre os programas de aceleração de startups no país foi possível identificar as principais características de tais programas e também questões abertas direcionadas a essas características, ou seja, aspectos ainda não delineados e que precisam ser elucidados a respeito dessas características. No entanto, para análise e generalização deste estudo é preciso considerar as limitações com relação à consulta de dados secundários incluindo a interpretação dos autores.

O trabalho contribui para um entendimento dos parâmetros e características dos programas de aceleração de startups no Brasil e pode auxiliar gestores no desenho de novos programas e avaliação crítica de iniciativas em andamento. Considera-se então para possíveis projetos de pesquisa sugestões como: fazer um levantamento dos pontos ainda em aberto ou obscurecido abordados neste artigo e então buscar por especialistas na área para um melhor entendimento; fazer um comparativo entre as características dos programas evidenciados no trabalho com 
programas de outros países; aprofundar as informações obtidas por esta pesquisa através de estudos de casos; entre outros.

A autora S.D.S.R. agradece a Fundação de Amparo a Pesquisa de Minas Gerais, pelo apoio financeiro recebido para apresentação e publicação deste artigo.

\section{REFERÊNCIAS}

ABREU, P., R., M.; CAMPOS, N., M.. O Panorama Das Aceleradoras De Startups No Brasil. Create Space Independent Publishing Plataform. USA. FGV/EAESP: Julho, 2016.

AGUILHAR, L.. Aceleradoras de startups ganham força no Brasil, mas precisam provar eficiência. Estado de São Paulo, São Paulo, 09 mar. 2014. Disponível em:< http://blogs.estadao.com.br/link/aceleradoras/>. Acesso em: 17 Mai. 2017.

ANDRADE, R., F.. Contexto do empreendedorismo no Brasil. In: GRANDO, N. (ORG). Empreendedorismo inovador como criar Startups de Tecnologia no Brasil. São Paulo, Editora Évora, cap.1, p.1-20, 2012.

ARRUDA, C.; NOGUEIRA, V.;COZZI, C.; COSTA, V.. Causa da Mortalidade de Startups Brasileiras: $O$ que fazer para aumentar as chances de sobrevivência no mercado?. Fundação Dom Cabral, Belo Horizonte, 2013.

AVENI, A.. Empreendedorismo Contemporâneo: Teorias e Tipologias. .1. ed. São Paulo: Atlas, 2014.

BLANK, S.; DORF, B.. The Startup Owner's Manual: The Step-by-Step Guide for Building a Great Company. K\&S Ranch, California, 2012.

COHEN, S.. What Do Accelerators Do? Insights from Incubators and Angels. Innovations: Technology, Governance, Globalization, Vol. 8 (3-4): p. 19-25, 2013.

COHEN, S.; HOCHBERG, Y. V. Accelerating startups: The seed accelerator phenomenon. SSRN Scholarly Paper ID 2418000. Rochester, NY: Social Science Research Network, 2014.

Confederação Nacional da Indústria (CNI). Pequenas e médias empresas inovadoras e startups / Confederação Nacional da Indústria, Instituto Euvaldo Lodi. - Brasília : CNI, 2016.

DEE, N.; GILL, D.; WEINBERG, C.; MCTAVISH, S.. Startup Support Programmes: What's The Difference?. Nesta. London, 2015.

DEMPWOLF, C. S.; AUER, J.; D'IPPOLITO, M.. Innovation accelerators: Defining characteristics among startup assistance organizations. Published online at www.sba.gov/advocacy: Small Business Administration, 2014.

DOLABELA, F.. Oficina do empreendedor: a metodologia de ensino que ajuda a transformar conhecimento em riqueza. São Paulo: Cultura Editores Associados, 1999.

DUARTE, F.; GOMES, L. A.V.; FRENKEL, J.; CLEMENTE, R.. Empreendedorismo e inovação em startups. In: PROENÇA, Adriano, LACERDA, Daniel Pacheco, ANTUNES JÚNIOR, J. V., TÁVORA JÚNIOR L. Gestão da Inovação e Competitividade no Brasil: Da Teoria para a Prática. Bookman, 2015.

FARIA, A. F.; ALMEIDA, A., F.; LAGE, A., C., A.;SEDIYANA, J., A., S.; SERPA, C., V. (Coordenadores). Estudo dos ambientes de inovação de Minas Gerais : empresas, incubadoras de empresas e parques tecnológicos. Viçosa, MG, NTG/UFV, 2017.

FEHDER, D. C.; HOCHBERG, Y. V. Accelerators and the Regional Supply of Venture Capital Investment. doi:http://dx.doi.org/10.2139/ssrn.2518668. 2014. 
HOFFMAN, D. L., RADOJEVICH-KELLEY, N.. Analysis of Accelerator Companies: An Exploratory Case Study of Their Programs, Processes, and Early Results. Small Business Institute Journal, 8(2), 54-70, 2012.

LEITE, E.. O Fenômeno do Empreendedorismo - $1^{\text {a }}$ edição. Saraiva, 2008.

MARTINS, C.. O papel das incubadoras de empresas do polo tecnológico de Florianópolis no desenvolvimento do processo de empreendedorismo inovador. 2013.269 f. Dissertação (Mestrado em Administração) - Universidade do Sul de Santa Catarina, Florianópolis, 2013.

MILLER, P., BOUND, K. (2011). The startup factories. Nesta. Disponível em: <http://www.nesta.org.uk/publications/startup-factories>. Acesso em 29 Jan. 2017.

OLIVEIRA, D. de P. R.. Empreendedorismo: vocação, capacitação e atuação direcionadas para o plano de negócios. Atlas, 2014.

PAUWELS, C.; CLARYSSE, B.; WRIGHT, M.; HOVE, J. V.. Understanding a new generation incubation model: The accelerator. 2014.

PERIN, B.. A Revolução das Startups: O Novo Mundo do Empreendedorismo de Alto Impacto. Alta Books; $1^{\text {a }}$ Edição, 2015.

RIES, E.. The Lean Startup: How Today's Entrepreneurs Use Continuous Innovation to Create Radically Successful Businesses. Hardcover, 2011.

RODRIGUEZ, J. A. H.. Start-up Development in Latin America: The Role of Venture Accelerators. Massachusetts Institute of Technology. Sloan School of Management, 2015.

ROMAN, V. B.. Estruturação Do Sistema De Desenvolvimento De Startups Em Uma Aceleradora Por Intermédio De Gestão De Portfólio. Dissertação (Mestrado Mestrado Profissional em Inovação Tecnológica e Propriedade Intelectual) - Universidade Federal de Minas Gerais, Belo Horizonte, 2017.

SALIDO, E.; SABÁS, M.; FREIXAS, P. The accelerator and incubator ecosystem in Europe. Telefónica Europe, 2013.

SARKAR, S.. O empreendedor Inovador: Faça diferente e conquiste seu espaço no mercado. Rio de Janeiro: Elsevier, 2008.

SMITH, W. S., \& HANNIGAN, T. J. (2015). Swinging for the fences: How do top accelerators impact the trajectories of new ventures? Paper to be presented at DRUID15, Rome, June 15-17, 2015.

STARTUP COMONS. Cornerstone Organizations. Disponível em: < http://www.startupcommons.org/customers.html>. Acessado em 27.01.2017

TASIC, I.; MONTORO-SÁNCHEZ, A.; CANO, M.D.. Startup accelerators: an overview of the current state of the acceleration phenomenon. XVIII Congresso AECA. Cartagena, 2015.

TAURION, C.. Mercado de empresas de alta tecnologia no país: riscos e oportunidades. In: GRANDO, N. (ORG). Empreendedorismo inovador como criar Startups de Tecnologia no Brasil. São Paulo, Editora Évora, 2012.

THIEL, P.; MASTERS, B.. De zero a um: O que aprender sobre empreendedorismo com o Vale do Silício. Editora Objetiva Ltda. Rio de Janeiro, 2014. 